\title{
QUEEN'S
UNIVERSITY
BELFAST
}

\section{Dropping the weight stigma: Nostalgia improves attitudes toward persons who are overweight}

Turner, R. N., Wildschut, T., \& Sedikides, C. (2012). Dropping the weight stigma: Nostalgia improves attitudes toward persons who are overweight. Journal of Experimental Social Psychology, 48(1), 130-137.

https://doi.org/10.1016/j.jesp.2011.09.007

Published in:

Journal of Experimental Social Psychology

Document Version:

Peer reviewed version

Queen's University Belfast - Research Portal:

Link to publication record in Queen's University Belfast Research Portal

\section{Publisher rights}

Copyright 2011 Elsevier.

This manuscript is distributed under a Creative Commons Attribution-NonCommercial-NoDerivs License

(https://creativecommons.org/licenses/by-nc-nd/4.0/), which permits distribution and reproduction for non-commercial purposes, provided the author and source are cited

\section{General rights}

Copyright for the publications made accessible via the Queen's University Belfast Research Portal is retained by the author(s) and / or other copyright owners and it is a condition of accessing these publications that users recognise and abide by the legal requirements associated with these rights.

Take down policy

The Research Portal is Queen's institutional repository that provides access to Queen's research output. Every effort has been made to ensure that content in the Research Portal does not infringe any person's rights, or applicable UK laws. If you discover content in the Research Portal that you believe breaches copyright or violates any law, please contact openaccess@qub.ac.uk. 
Fighting Off the Weight Stigma through Nostalgia 1

Running Head: FIGHTING OFF THE WEIGHT STIGMA THROUGH NOSTALGIA

Fighting off the Weight Stigma:

Nostalgia Improves Attitudes toward the Overweight

Rhiannon Turner

Constantine Sedikides

Tim Wildschut

WORD COUNT: Abstract $=148$; Text $=2489$; References $=28$ 


\begin{abstract}
Weight stigma, a negative attitude toward the overweight, can lead to emotional detriment (increased vulnerability to depression and anxiety, decreased self-esteem) and discriminatory practices (denial of employment, lower wages, refusal of job promotion or college admission, healthcare deprivation), which have increased in the United States by $66 \%$ in the past decade. We report an experiment that implicates nostalgia as a mode for weight stigma reduction. We hypothesized and found that nostalgia about an encounter with an overweight individual improves attitudes toward the group overweight. Undergraduates who recalled a nostalgic (vs. ordinary) interaction with an overweight individual subsequently showed greater inclusion of the outgroup (the overweight) in the self, greater outgroup trust, and more positive affective, cognitive, and behavioral attitudes towards the outgroup. The effect of nostalgia on outgroup attitudes was mediated by inclusion of the outgroup in the self and increased outgroup trust. The findings have interventional potential.
\end{abstract}

KEYWORDS: Nostalgia, Overweight individuals, Weight stigma, Inclusion in the Self, Outgroup Trust, Prejudice 
Overweight individuals are perceived as lazy, socially inept, unhappy, ugly, and stupid (Puhl \& Brownell, 2001; Puhl \& Latner, 2007). This negative attitude toward the overweight, or weight stigma, has profound consequences including increased vulnerability to depression and anxiety, and decreased self-esteem (Puhl \& Latner, 2007). Moreover, weight stigma leads to discrimination. Overweight children are victimized, verbally abused, and bullied or aggressed against, whereas overweight adults are denied employment, given lower wages, refused job promotion or college admission, and deprived of healthcare (Puhl, Andreyeva, \& Brownell, 2008; Puhl \& Brownell, 2001; Puhl \& Latner, 2007). Weight discrimination has increased by $66 \%$ in the past decade in the United States, and is now at least as prevalent as racial discrimination and, in some case, more prevalent than gender or age discrimination (Andreyeva, Puhl, \& Brownell, 2008; Puhl et al., 2008). The root of discriminatory practices, weight stigma, needs to be tackled. We propose and test the idea that nostalgia reduces weight stigma.

\section{Nostalgia}

Nostalgia, "a sentimental longing for the past" (The New Oxford Dictionary of English, 1998, p. 1266), was historically regarded a brain malfunction, psychiatric disorder, or variant of depression (Sedikides, Wildschut, \& Baden, 2004). Recent research, however, suggests that nostalgia is a predominantly positive emotion that serves vital psychological functions. One such function is social connectedness.

The content of nostalgic narratives is substantially more positive than negative, as naturalistic and laboratory studies indicate (Wildschut, Sedikides, Arndt, \& Routledge, 2006). Furthermore, nostalgic narratives are social: during nostalgic reverie, figures from the past become part of one's present (Sedikides, Wildschut, Arndt, \& Routledge, 2008). Also, nostalgia, when experimentally induced, engenders perceptions of social support, increases estimates of the number of friends one has, nurtures feelings of being protected and loved, reduces attachment anxiety and attachment avoidance, and elevates perceptions of social competence (Wildschut et al., 2006; Wildschut, 
Sedikides, Routledge, Arndt, \& Cordaro, 2010; Zhou, Sedikides, Wildschut, \& Gao, 2008). In all, nostalgia, through its positivity and connectedness, gives rise to "an expansive state of mind" (Kaplan, 1987, p. 465) or an approach orientation (Stephan, Sedikides, Wildschut, \& Routledge, 2010), whereby ones opens up to the possibility of new relationships or others in general.

Research on intergroup contact suggests that social interactions between members of different groups must be positive in order to improve intergroup relations (Pettigrew \& Tropp, 2006). We capitalized on this finding to formulate our hypotheses regarding the role of nostalgia in reducing the weight stigma or improving attitudes toward the overweight.

\section{Consequences of Nostalgia for Outgroup Attitudes}

Inclusion of others in the self is a marker of interpersonal closeness (Aron, Aron, \& Smollan, 1992). When persons become nostalgic about a known outgroup member, an increased sense of social connectedness will result in increased inclusion of that outgroup member in the self. Provided the group membership of that individual is salient (Brown \& Hewstone, 2005), inclusion of an outgroup member in the self will result in the inclusion of the entire outgroup in the self. Potential benefits of this are greater empathy with outgroup members' problems, more pride in their successes, and a more positive outgroup evaluation (Aron, Aron, Tudor, \& Nelson, 1991). Thus, nostalgia about an overweight individual will lead to inclusion in the self of the group overweight, which in turn will result in improved attitudes toward the overweight.

Nostalgia about an outgroup member may also generate outgroup trust. Trust is a positive expectation about another's intentions and behavior (Turner et al., in press). If perceivers experience an increased sense of social connectedness to an outgroup member as a result of nostalgia, they will feel more trusting towards that individual. Provided group membership of that individual remains salient (Brown \& Hewstone, 2005), perceivers will generalize trust from the individual to the entire outgroup. Benefits of trust include greater positivity toward the outgroup, and enhanced communication and cooperation (Dovidio, Gaertner, Kawakami, \&Hodson, 2002). 
Nostalgia, then, about an overweight individual will lead to increased trust of the group overweight, which in turn will result in improved attitudes toward the overweight.

\section{Method}

\section{Participants and Procedure}

Sixty University of Leeds undergraduates (37 female, 23 male; age range: 19-21; none visibly overweight) were randomly assigned to the nostalgia or control condition (instructions modified from Wildschut et al., 2006) and were seated in separate cubicles. In the nostalgia condition, they learned: "According to the Oxford Dictionary, 'nostalgia' is defined as a 'sentimental longing for the past.' Please bring to mind a nostalgic event in your life that involved interacting with an overweight person. Specifically, try to think of a past event involving an overweight person that makes you feel most nostalgic. Now we would like you to spend five minutes imagining that you are back at this nostalgic event. Try and immerse yourself into this nostalgic event, remembering what it was like and how you felt at the time you interacted with the overweight person."

In the control condition, participants learned: “This is a study on autobiographical memory - that is, on your memory about your past. Please bring to mind an ordinary event in your life that involved interacting with an overweight person. Specifically, try to think of a past event involving an overweight person that is ordinary. Bring to mind an objective record of this event and think it through as though you were a scientist or historian recording factual details. Now we would like you to spend five minutes imagining that you are back at this event. Try and immerse yourself into this autobiographical event, trying to remember exactly what happened at the time you interacted with the overweight person." Next, participants wrote down a description of the event and completed a manipulation check and the dependent measures.

\section{Manipulation Check}


Participants responded to three items (Wildschut et al., 2006): "Right now, I am feeling quite nostalgic," "Right now, I am having nostalgic feelings," and "I feel nostalgic at the moment" (1=strongly disagree, 6=strongly agree; alpha=.97). A higher score reflected greater nostalgia.

\section{Mediators}

Inclusion of the outgroup in the self. Participants indicated the nature of their relationship with the outgroup for each of seven pairs of overlapping circles (Aron et al., 1992). The greater the overlap between the circles, the greater the inclusion of the outgroup in the self.

Outgroup trust. Participants responded to five items (alpha=.83; adapted from Tam, Hewstone, Kenworthy, \& Cairns, 2009): "Right now, I am able to trust an overweight person as much as any other person" (1=strongly disagree, 7=strongly agree), "Right now, I am able to trust an overweight person with personal information about myself' (1=strongly disagree, 7=strongly agree), "Do you think most overweight people would try to take advantage of you if they got the chance, or would they try to be fair? (1=take advantage, 7=be fair), "Would you say that most of the time overweight people try to be helpful, or that they are mostly just looking out for themselves?" (1=out for themselves, $7=$ helpful $)$, and "Generally speaking, would you say that overweight people can be trusted, or that you can't be too careful?" (1=can't be too careful, $7=c a n$ be trusted). A higher score reflected greater outgroup trust.

\section{Outgroup Attitudes}

According to the tripartite model, attitudes have three components: affective, cognitive, and behavioral (Eagly \& Chaiken, 1993).

Affective component. Participants were instructed: "Please indicate how you feel about overweight people right now. For each of the following scales, circle the number that best reflects how you feel." They were then presented with five seven-point semantic differential items: cold warm, negative - positive, hostile - friendly, contempt - respect, disgust - admiration (alpha=.91; 
Wright, Aron, McLaughlin-Volpe, \& Ropp, 1997). A higher score reflected a more positive outgroup attitude.

Cognitive component. Participants were instructed: "Please rate the following statements by circling the number which best describes how much control you believe an individual has over their weight." They were then asked to respond to five statements (Musher-Eizenman et al., 2004): "People have control over their weight," "If a person is overweight, it is his or her fault," "People are overweight because they eat too much," "People are overweight because they don't exercise," and "Overweight people can become thin if they really try" (1=not at all, 9=very much; alpha $=.80$ ). Responses on items were then reversed so that a higher score reflected a more positive cognitive attitude (a perception that overweight individuals are not responsible for their size).

Behavioral component. Participants were instructed (Mackie, Devos, \& Smith, 2000): "Please rate the following statements by circling the number which best describes how you react to overweight people. Right now, when thinking of overweight people I want to... "Talk to them," "Find out more about them," "Spend time with them," "Avoid them," "Keep them at a distance," and "Have nothing to do with them" (1=does not describe my usual actions, $9=$ describes my usual actions; latter 3 items reversed; alpha=.82).

\section{Results}

\section{Manipulation Check}

As intended, participants were more nostalgic in the nostalgia $(M=4.63, S D=.78)$ than control $(M=2.11, S D=1.33)$ condition, $F(1,58)=79.65, p<.0005, d=2.31$.

\section{Affective, Cognitive, and Behavioral Components of Outgroup Attitudes}

Nostalgic $(M=4.29, S D=1.12)$ relative to control $(M=3.34, S D=1.06)$ participants held a more positive attitude towards overweight people, $F(1,58)=11.38, p<.001, d=.87$. Nostalgic $(M=2.98, S D=1.02)$, more than control $(M=1.19, S D=.82)$, participants believed that overweight 
people were not responsible for their excess weight, $F(1,58)=10.71, p<.002, d=.84$. Finally, nostalgic $(M=5.20, S D=1.38)$ relative to control $(M=3.92, S D=1.34)$ participants manifested more positive or approach behavioral tendencies toward overweight people, $F(1,58)=13.19, p<.001$, $d=.94$.

\section{Formation of a Latent Variable}

Nostalgia influenced all three components of outgroup attitudes. Furthermore, these components were correlated: affective attitude-behavioral attitude, $r(58)=.73, p<.0005$; affective attitude-cognitive attitude, $r(58)=.39, p<.002$; behavioral attitude-cognitive attitude, $r(58)=.55$, $p<.0005$. We therefore treated the average scores on the affective, cognitive, and behavioral components as indicators of a latent variable representing outgroup attitudes. We proceeded to conduct structural equation modeling (AMOS 7), testing for mediation. We treated all other variables as manifest variables and measured them with a single item. (Table 1 presents correlations between components of the latent attitude variable and each other construct.) We assessed the goodness-of-fit of each model using the chi-square test $\left(\chi^{2}\right)$, the root mean square error of approximation (RMSEA), and the comparative fit index (CFI). A good fit is indicated by a non-significant chi-square test, an RMSEA value of less than .06, and a CFI value greater than 0.95 (Hu \& Bentler, 1999).

\section{Inclusion of the Outgroup in the Self as a Mediator}

We hypothesized that inclusion of the outgroup in the self would mediate the effect of nostalgia on outgroup attitudes. The effect of condition on outgroup attitudes was significant, $\beta=.61, p<.0005$. We next tested a fully mediated model. Nostalgic participants $(M=3.43$, $S D=1.33)$ reported greater inclusion of the outgroup in the self than control participants $(M=2.03$, $S D=1.54), \beta=.44, F(1,58)=14.17, p<.0005, d=.97$. In turn, inclusion of the outgroup in the self predicted outgroup attitudes, $\beta=.81, p<.0005$. The model fit was acceptable: $\chi^{2}(5)=7.85, p=.16$; RMSEA $=.09, \mathrm{CFI}=.96$, indicating that inclusion of the outgroup in the self mediates the effect of 
nostalgia on outgroup attitude. The model explained $65 \%$ of the variance in outgroup attitude. As a subsequent test, we included the direct path in the model. This path was significantly weaker, $\beta=.31, p<.01$, than when the mediator was not controlled for $(\beta=.61, p<.0005)$. Bootstrapping analysis confirmed that the indirect effect of nostalgia via inclusion of the outgroup in the self was significant: mean bootstrap estimate=.53, 95\% confidence internal=.002 /.67. A significant Sobel test further confirmed mediation, $z=2.95, p<.003$ (Figure 1).

\section{Outgroup Trust as a Mediator}

We hypothesized that outgroup trust would mediate the effect of nostalgia on outgroup attitudes. In the fully mediated model, nostalgic participants $(M=5.33, S D=1.06)$ reported more outgroup trust than control participants $(M=4.15, S D=1.33), \beta=.45, F(1,58)=14.44, p<.0005$, $d=.98$. In turn, outgroup trust predicted outgroup attitude, $\beta=.75, p<.0005$. The model fit was acceptable: $\chi^{2}(5)=8.14, p=.15$; RMSEA $=.10, \mathrm{CFI}=.96$, indicating that inclusion of the outgroup in the self mediates the effect of trust on outgroup attitude. The model explained $56 \%$ of the variance in outgroup attitude. Next, we included the direct path in the model. This path was significantly weaker, $\beta=.34, p<.01$, than when the mediator was not controlled for. Bootstrapping analysis confirmed that the indirect effect of nostalgia via trust was significant: mean bootstrap estimate $=.49,95 \%$ confidence internal $=.003 / .69$. The Sobel test also confirmed mediation: $z=2.42, p<.02$ (Figure 2).

\section{Comparative Strength of Mediators}

Finally, we tested a model in which we included the predictor (condition) and both mediators (inclusion of outgroup in the self, outgroup trust) in the analysis simultaneously, excluding a priori the direct path from condition to outgroup attitude, in order to assess the comparative strength of mediators. Inclusion of the outgroup in the self had a significant association with outgroup attitude, $\beta=.55, p<.0005$, and so did outgroup trust, $\beta=.41, p<.003$. Next, we included the direct path in the model. This path was significantly weaker, $\beta=.23, p<.05$, 
than when the mediator was not controlled for. Bootstrapping analysis confirmed that the indirect effects of nostalgia via inclusion of outgroup in the self (bootstrap estimate $=.37,95 \%$ confidence interval $=.002 / .58)$ and outgroup trust $($ bootstrap estimate $=.26,95 \%$ confidence interval $=$ .002/.56) were significant. Sobel tests further confirmed mediation via inclusion of outgroup in the self, $z=2.56, p<.01$, and outgroup trust, $z=2.09, p<.04$. The predictor and mediators explained $75 \%$ of the variance in outgroup attitude (Figure 3). The tested model fit the data well: $\chi^{2}(7)$ $=5.53, p=.60 ; \mathrm{RMSEA}=.01 ; \mathrm{CFI}=.99$.

\section{Discussion}

Nostalgia improved outgroup attitudes. Nostalgia fostered inclusion of the outgroup overweight in the self and strengthened trust toward the overweight, which in turn increased the positivity of attitudes toward the overweight (encompassing affective, cognitive, and behavioural components). These findings represent a substantial theoretical advancement. They illustrate that nostalgia benefits not only interpersonal relationships (Wildschut et al., 2006, 2010; Zhou et al., 2008), but also society more generally (weight stigma reduction). The findings also specify mechanisms through which nostalgia combats the weight stigma.

Moreover, these findings also have interventional implications. Arguably, nostalgia is easier to implement and perhaps sustain than actual intergroup contact (Pettigrew \& Tropp, 2006). The same can be said about imagined intergroup contact, where participants who imagine interacting with an outgroup member subsequently show more positive outgroup attitudes than control participants (Crisp \& Turner, 2009; Turner, Crisp, \& Lambert, 2007). Such research has not drawn on participants' autobiographical memories as a source of imagined contact. Thus, persons might not spontaneously engage in this type of abstract mental imagery, this type of mental imagery is rather impoverished (lacking in texture and affect), and any intervention might be difficult to maintain (low adherence) and might produce suboptimal results. Yet, the present research provides insight into how imagined contact interventions may be implemented 
successfully by (1) capitalizing upon the known propensity for most persons to recall nostalgic memories on a regular basis (Wildschut et al., 2006) and (2) mining the rich deposits of nostalgic memories the undoubtedly will involve outgroup members. 


\section{References}

Andreyeva, T., Puhl, R. M., \& Brownell, K. D. (2008). Changes in perceived weight discrimination among Americans. Obesity, 16, 1129-1134.

Aron, A., Aron, E. N., Tudor, M., \& Nelson, G. (1991).Close relationships as including other in the self. Journal of Personality and Social Psychology, 60, 241-253.

Aron, A., Aron, E. N., \& Smollan, D. (1992). Inclusion of other in the self scale and the structure of interpersonal closeness. Journal of Personality and Social Psychology, 63, 596-612.

Brown, R., \& Hewstone, H. (2005). An integrative theory of intergroup contact. Advances in Experimental Social Psychology, 37, 255-343.

Cohen, J. (1988). Statistical power analysis for the behavioral sciences. Hillsdale, NJ: Erlbaum.

Crisp, R. J., \& Turner, R. N. (2009). Can imagined interactions produce positive perceptions? Reducing prejudice through simulated social contact. American Psychologist, 64, 231-240.

Dovidio, J. F., Gaertner, S. L., Kawakami, K., \& Hodson, G. (2002). Why can't we just get along? Interpersonal biases and interracial distrust. Cultural Diversity and Ethnic Minority Psychology, 8, 88-102.

Eagly, A. H., \& Chaiken, S. (1993). The psychology of attitudes. Orlando, FL: Harcourt Brace. Hu, L., \& Bentler, P. M. (1999). Cutoff criteria for fit indexes in covariance structure analysis: Conventional criteria versus new alternatives. Structural Equation Modeling, 6, 1-55.

Mackie, D. M., Devos, T. \& Smith., E. R. (2000). Intergroup emotions: Explaining offensive action tendencies in an intergroup context. Journal of Personality and Social Psychology, 79, 602-616.

Musher-Eizenman, D. R., Holub, S. C., Miller, A. B., Goldstein, S. E., \& Leeper, L. (2004). Body stigmatization in preschool children: The role of control attributions. Journal of Pediatric Psychology, 29, 613-620. 
Pettigrew, T. F., \& Tropp, L. R. (2006). A meta-analytic test of intergroup contact theory. Journal of Personality and Social Psychology, 90, 751-783.

Puhl, R. M., Andreyeva, T., \& Brownell, K. D. (2008). Perceptions of weight discrimination: Prevalence and comparison to race and gender discrimination in America. International Journal of Obesity, 32, 992-1001.

Puhl, R. M., \& Brownell, K. (2001). Bias, discrimination, and obesity. Obesity Research, 9, 788805.

Puhl, R. M., \& Latner, J. (2007). Obesity, stigma, and the health of the nation's children. Psychological Bulletin, 133, 557-580.

Sedikides, C., Wildschut, T., \& Baden, D. (2004). Nostalgia: Conceptual issues and existential functions. In J. Greenberg, S Koole, \& T. Pyszczynski (Eds.), Handbook of experimental existential psychology (pp. 200-214). New York, NY: Guilford Press.

Sedikides, C., Wildschut, T., Arndt, J., \&Routledge, C. (2008). Nostalgia: Past, present and future. Current Directions in Psychological Science, 17, 304-307.

Stephan, E., Sedikides, C., Wildschut, T., \& Routledge, C. (2010). Nostalgia regulates avoidance and approach motivation. Unpublished manuscript, University of Southampton.

Tam, T., Hewstone, M., Kenworthy, J., \& Cairns, E. (2009). Intergroup trust in Northern Ireland. Personality and Social Psychology Bulletin, 35, 45-59.

The New Oxford Dictionary of English. (1998). Oxford, England: Oxford University Press.

Turner, R. N., Crisp, R. J., \& Lambert, E. (2007). Imagining intergroup contact can improve intergroup attitudes. Group Processes and Intergroup Relations, 10, 427-441.

Turner, R. N., Hewstone, M., Swart, H., Tam, T., Myers, E., \&Tausch, N. (in press). Promoting intergroup trust among adolescents and young adults. In K. Rotenberg (Ed.), Interpersonal trust during childhood and adolescence. Cambridge, England: Cambridge University Press. 
Turner, R. N., Hewstone, M., \& Voci, A. (2007). Reducing explicit and implicit prejudice via direct and extended contact: The mediating role of self-disclosure and intergroup anxiety. Journal of Personality and Social Psychology, 93, 369-388

Turner, R. N., Hewstone, M., Voci, A., \& Vonofakou, C. (2008). A test of the extended intergroup contact hypothesis: The mediating role of intergroup anxiety, perceived ingroup and outgroup norms, and inclusion of the outgroup in the self. Journal of Personality and Social Psychology, 95, 843-860.

Wildschut, T., Sedikides, C., Arndt, J., \&Routledge, C. (2006). Nostalgia: Content, triggers, functions. Journal of Personality and Social Psychology, 91, 975-993.

Wildschut, T., Sedikides, C., Routledge, C., Arndt, J., \& Cordaro, P. (2010). Nostalgia as a repository of social connectedness: The role of attachment-related avoidance. Journal of Personality and Social Psychology, 98, 573-586.

Wright, S. C., Aron, A., McLaughlin-Volpe, T., \& Ropp, S. A. (1997). The extended contact effect: Knowledge of cross-group friendships and prejudice. Journal of Personality and Social Psychology, 73, 73-90.

Zhou, X., Sedikides, C., Wildschut, C., \& Gao, D-G. (2008). Counteracting loneliness: On the restorative function of nostalgia. Psychological Science, 19, 1023-1029. 
Table 1.

Correlation matrix between latent variables for Experiment 2.

\begin{tabular}{lllllll}
\hline & 1 & 2 & 3 & 5 & 6 & 7 \\
\hline 1. Nostalgia vs. Control & 1.00 & & & & & \\
2. Inclusion of outgroup in self & $.44^{* * *}$ & 1.00 & & & & \\
3. Intergroup trust & $.45^{* * *}$ & $.61^{* * *}$ & 1.00 & & & \\
5. Attitude (1) & $.41^{* * *}$ & $.59^{* * *}$ & $.55^{* * *}$ & 1.00 & & \\
6. Attitude (2) & $.40^{* *}$ & $.38^{* *}$ & $.36^{* *}$ & $.39 * *$ & 1.00 & \\
7. Attitude (3) & $.43^{* * *}$ & $.59^{* * *}$ & $-.54^{* * *}$ & $.51^{* * *}$ & $.38^{* *}$ & 1.00 \\
\hline
\end{tabular}

Note: Attitude 1=Affective components, Attitude 2=Cognitive components, Attitude $3=$ Behavioral components

$* p<.05 ; * * p<.01 ; * * * p<.001 ; N=60$ 
Figure captions

Figure 1. Single mediation model showing inclusion of the outgroup in the self as a mediator of the effect of nostalgia on outgroup attitude.

Note: All coefficients=standardized betas. Figure in parenthesis on direct path is beta when controlling for mediators. $* p<.05 ; * * p<.01 ; * * * p<.001 ; N=60$.

Figure 2. Single mediation model showing outgroup trust as a mediator of the effect of nostalgia on outgroup attitude.

Note: All coefficients=standardized betas. Figure in parenthesis on direct path is beta when controlling for mediators. $* p<.05 ; * * p<.01 ; * * * p<.001 ; N=60$.

Figure 3. Double mediation model showing inclusion of the outgroup in the self and outgroup trust as mediators of the effect of nostalgia on outgroup attitude.

Note: All coefficients=standardized betas. Figure in parenthesis on direct path is beta when controlling for mediators. $* p<.05 ; * * p<.01 ; * * * p<.001 ; N=60$. 


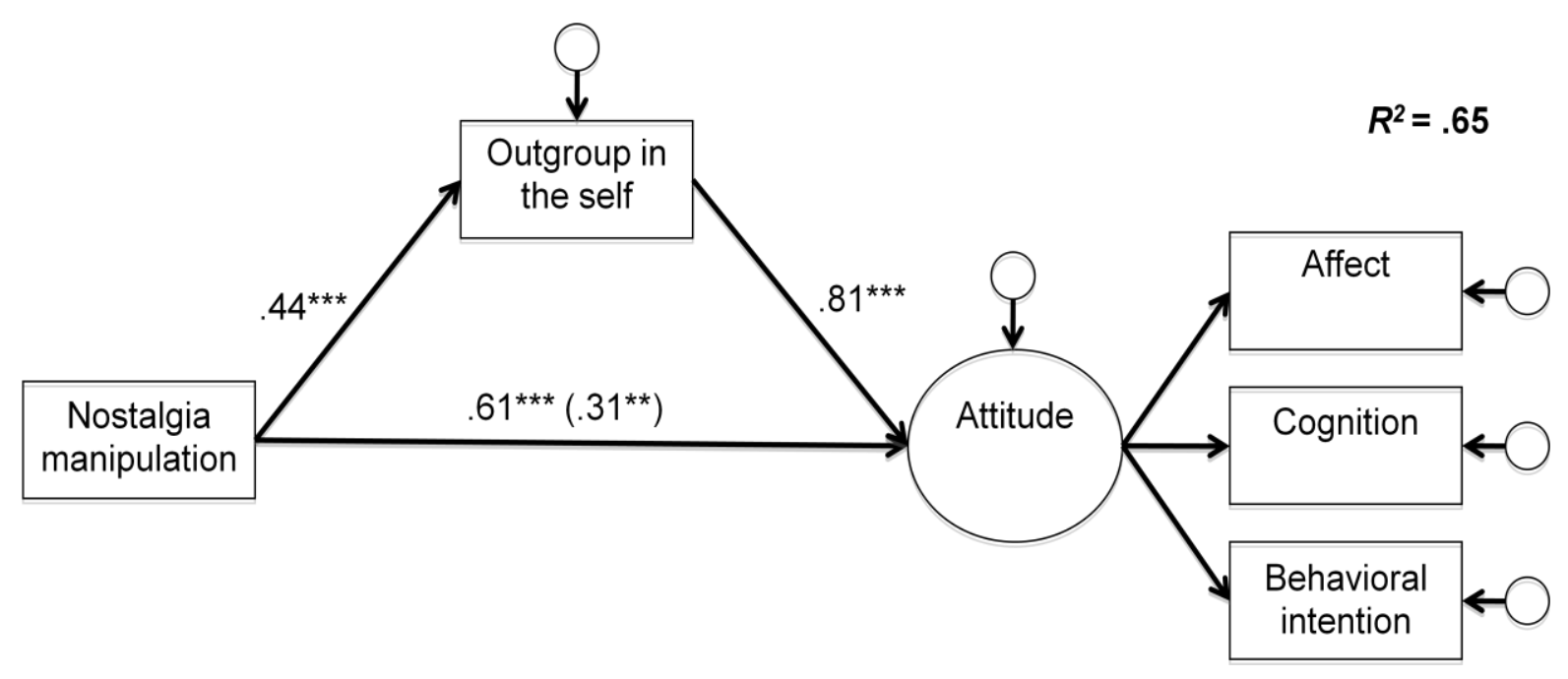




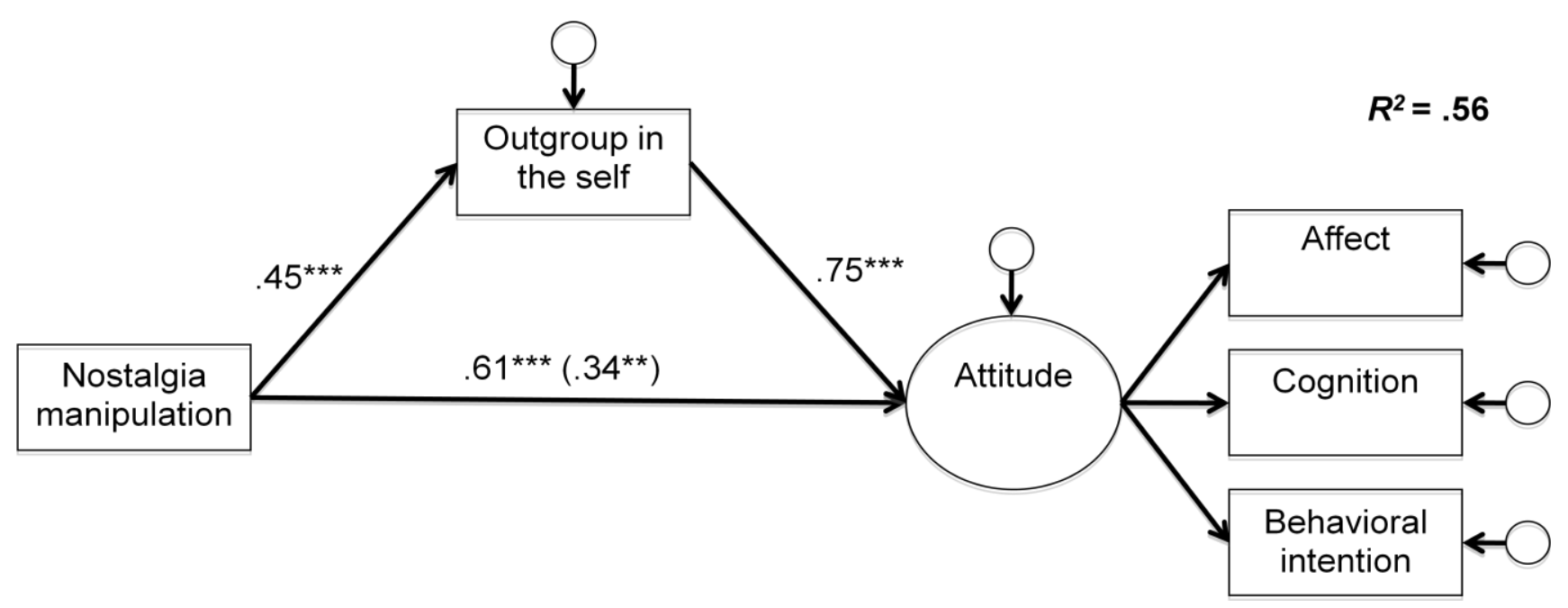




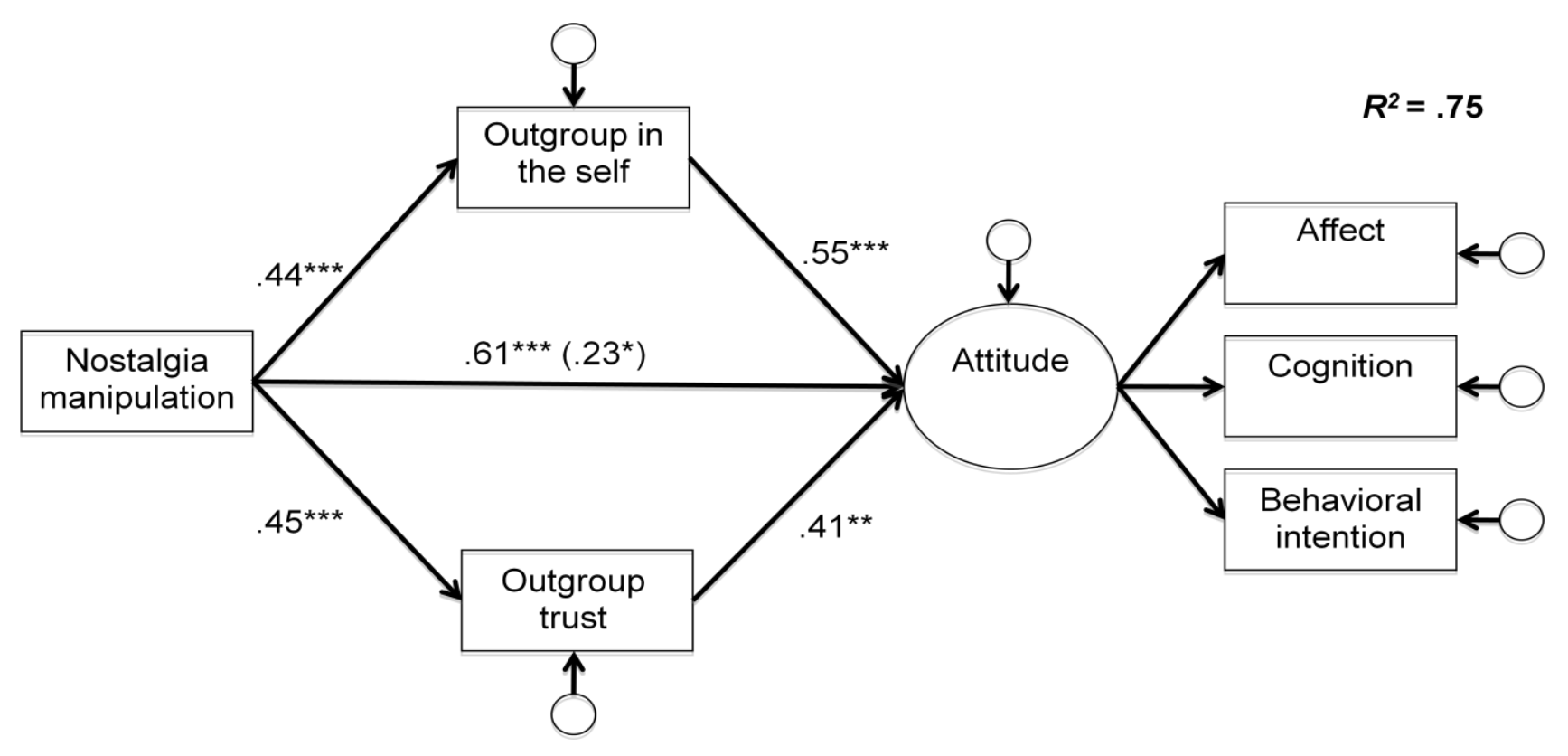

